\title{
A statin a day keeps the doctor away: comparative proverb assessment modelling study
}

\author{
(C) (1) $\Theta$ OPEN ACCESS \\ Adam D M Briggs academic clinical fellow, Anja Mizdrak researcher, Peter Scarborough senior \\ researcher
}

BHF Health Promotion Research Group, Nuffield Department of Population Health, University of Oxford, Headington, Oxford OX3 7LF, UK

\begin{abstract}
Objective To model the effect on UK vascular mortality of all adults over 50 years old being prescribed either a statin or an apple a day.

Design Comparative proverb assessment modelling study.

Setting United Kingdom.

Population Adults aged over 50 years.

Intervention Either a statin a day for people not already taking a statin or an apple a day for everyone, assuming $70 \%$ compliance and no change in calorie consumption. The modelling used routinely available UK population datasets; parameters describing the relations between statins, apples, and health were derived from meta-analyses.

Main outcome measure Mortality due to vascular disease.

Results The estimated annual reduction in deaths from vascular disease of a statin a day, assuming $70 \%$ compliance and a reduction in vascular mortality of $12 \%$ (95\% confidence interval $9 \%$ to $16 \%$ ) per $1.0 \mathrm{mmol} / \mathrm{L}$ reduction in low density lipoprotein cholesterol, is 9400 (7000 to 12 500). The equivalent reduction from an apple a day, modelled using the PRIME model (assuming an apple weighs $100 \mathrm{~g}$ and that overall calorie consumption remains constant) is 8500 (95\% credible interval 6200 to $10800)$.

Conclusions Both nutritional and pharmaceutical approaches to the prevention of vascular disease may have the potential to reduce UK mortality significantly. With similar reductions in mortality, a 150 year old health promotion message is able to match modern medicine and is likely to have fewer side effects.
\end{abstract}

\section{Introduction}

"An apple a day keeps the doctor away," a public health message delivered by parents and teachers since the 19 th century, ${ }^{1}$ is an example of how concise, clear, and accurate Victorian health promotion can truly stand the test of time, whereas other Victorian practices - such as the use of leeches in primary care-have fallen away.
Today in the United Kingdom, lifestyle changes (such as increasing levels of physical activity or changing diet) are the recommended first step for primary prevention of vascular disease. ${ }^{2}$ Increasingly, however, calls are being made for greater use of drugs in primary prevention, perhaps the best known example being Wald and Law proposing the polypill in 2003. ${ }^{3}$ In the UK, the only drug class recommended for primary prevention at a population level is the hydroxymethyl glutaryl coenzyme A reductase inhibitors, or statins, and this is only for people at $20 \%$ or greater risk of a cardiovascular event in the next 10 years. ${ }^{2}$ Recent meta-analyses have indicated similar relative benefits to patients with a five year risk of a major vascular event of less than $1 \%$ to those at greater than $20 \%$ risk, without evidence of significant harm. ${ }^{4}$ This has led to calls to use statins for cardiovascular disease prevention at the population level, particularly for people aged 50 years and over. ${ }^{5}$ We set out to test how almost 150 years of Victorian wisdom might compare with the more widespread use of statins in primary prevention. We modelled the effect on vascular mortality of prescribing everybody in the UK over 50 years old either an apple (Malus domestica) a day or a statin a day, estimated the number of adverse events, and compared the subsequent drug, or fruit, costs.

\section{Methods}

Data on the effect on vascular mortality (any stroke, cardiac death, or other vascular death) of the UK population of a statin a day came from the Cholesterol Treatment Trialists' meta-analysis, which found that reducing cholesterol with a statin reduces the relative risk of vascular mortality by $12 \%$ (95\% confidence interval $9 \%$ to $16 \%$ ) per $1.0 \mathrm{mmol} / \mathrm{L}$ reduction in low density lipoprotein cholesterol and that on average this is reduced by $1.08 \mathrm{mmol} / \mathrm{L}$ over a year of treatment. ${ }^{4} \mathrm{We}$ applied this annual reduction to age and sex specific vascular mortality rates for the UK population aged 50 years and over who are not taking a statin for primary disease prevention as reported in the 
Health Survey for England (stratified by sex and five year age categories, with age and sex specific statin uptake for Scotland, Wales, and Northern Ireland assumed to be the same as for England). ${ }^{6-10}$ We assumed $70 \%$ compliance on a conservative basis; this was the lower of the two compliance values reported by Taylor et al in their recent Cochrane review (77\% for statins, $70 \%$ for placebo). ${ }^{11}$ We calculated the reduction in deaths from vascular disease as the difference between the number of vascular deaths in the population not taking statins, using current age and sex specific mortality rates, and the number of deaths when assuming the new mortality rates. We calculated $95 \%$ credible intervals by applying the $95 \%$ confidence intervals surrounding the reduction in vascular mortality identified by the Cholesterol Treatment Trialists of $9 \%$ to $16 \%{ }^{4}$

We modelled the effect on vascular mortality (cerebrovascular disease, ischaemic heart disease, heart failure, and abdominal aortic aneurysm) of an apple a day on the entire UK population aged 50 years and over (whether taking statins or not) by using PRIME, a widely published comparative risk assessment model (see web appendix for more details). ${ }^{12-15}$ This uses meta-analyses of studies to parameterise the relation between a wide range of nutritional factors (g/day of fruit, vegetables, salt, and fibre; percentage of total energy derived from total fat,

monounsaturated fatty acids, polyunsaturated fatty acids, saturated fatty acids, trans fatty acids, and dietary cholesterol; and total energy intake in $\mathrm{kcal} / \mathrm{day}$ ) and chronic disease mortality. On a conservative basis, we assumed apples to weigh $100 \mathrm{~g}$, although weighing of various varieties identified examples of up to $250 \mathrm{~g}$ (authors' measurements using household scales and a range of apples). Baseline population diet and the nutritional composition of apples came from the Living Costs and Food Survey 2010, in which the weekly weight of apples consumed was assumed to increase by $700 \mathrm{~g}$ (see table $1 \Downarrow$ for the nutritional information). ${ }^{16} \mathrm{We}$ held the total calorie intake constant, assuming that the addition of calories consumed in apple form would lead to a proportionate decrease in calories consumed elsewhere in the diet. We assumed the effect on health of consuming an extra apple a day to be the same irrespective of baseline apple consumption, as described in the underlying meta-analyses describing the relations between fruit and vegetable consumption and cardiovascular disease. ${ }^{17}{ }^{18} \mathrm{We}$ assumed compliance to be $70 \%$ and prescribing of statins not to change. We calculated $95 \%$ credible intervals by using 5000 iterations of a Monte Carlo analysis to account for the variation in parameters describing the relations between different dietary components and mortality from cerebrovascular disease, ischaemic heart disease, heart failure, and abdominal aortic aneurysm (see web appendix for additional information on PRIME).

We modelled side effects of statins by using the Cholesterol Treatment Trialists' reports of statins leading to an excess incidence of myopathy of $0.5 / 1000$ patients over five years, of rhabdomyolysis of $0.1 / 1000$ over five years, and of diabetes mellitus of $0.1 \%$ a year (the reported increased incidence of haemorrhagic strokes was not modelled because if fatal, these would be incorporated in the overall effect on vascular mortality). ${ }^{4}$ We applied these to the extra population aged over 50 who would be taking statins, assuming $70 \%$ compliance, to give an estimated number of additional adverse events per year. No side effects were modelled for increased apple consumption; aside from the distress caused by a bruised apple, and the theoretical risk of identifying half a worm inside, apple related adverse events are not widely recognised. People with an apple allergy could be prescribed an alternative less allergenic fruit with similar health benefits. ${ }^{17} 18$
We obtained costs of statins from the British National Formulary, ${ }^{19}$ applying the cost of a prescription of simvastatin $40 \mathrm{mg}$ of $£ 1.24 / \mathrm{month}$ to the number of extra people taking the drug to identify the total annual cost. The cost of an apple came from the Department for Environment, Food and Rural Affairs' weekly fruit and vegetable prices for the cheapest variety of dessert apple (assuming the NHS would want to purchase at the lowest price) of 47 pence/kilo, or approximately 4.7 pence/apple assuming these apples are on the smaller side. ${ }^{20}$ No costs were estimated for general practice appointments or the management of any side effects.

Sensitivity analyses investigated the effect of prescribing statins or apples to everybody over 30 years rather than 50 years (the age from which the QRISK2-2011 scoring system is validated to predict 10 year cardiovascular risk ${ }^{21}$ ); the effect of $90 \%$ compliance with apple prescriptions (given that just $10 \%$ of the adult population manage less than one portion of fruit and vegetables a day ${ }^{22}$ ); and removing the assumption that the remainder of the diet, except calorie intake, would be adjusted to compensate for the additional apple.

\section{Results}

We estimate that 5.2 million people are eligible for statin treatment in the UK, with an extra 17.6 million people being offered it should it become recommended as a primary prevention measure for all adults aged over 50. Assuming $70 \%$ compliance, offering statins to 17.6 million more adults would result in a reduction in the annual number of vascular deaths by 9400 (95\% credible interval 7000 to 12500 ).

Table $2 \Downarrow$ shows the baseline daily UK diet and the diet after inclusion of an apple a day (assuming no change to calorie consumption).$^{16}$ Applying this diet to $70 \%$ of the total UK population aged over 50 years ( $70 \%$ of the 22 million people in the UK aged over 50 years), we estimate the annual number of vascular deaths averted or delayed to be 8500 (95\% credible interval 6200 to 10800 ). Prescribing statins to everyone over the age of 50 years is predicted to lead to 1200 excess cases of myopathy, 200 cases of rhabdomyolysis, and 12300 diagnoses of diabetes mellitus. The total extra cost of statin treatment from the drug alone is estimated at $£ 180 \mathrm{~m}$ ( $€ 217 \mathrm{~m} ; \$ 295 \mathrm{~m})$, compared with $£ 260 \mathrm{~m}$ for the apples.

\section{Sensitivity analyses}

Prescribing either apples or statins to everybody over 30 years old is estimated to reduce the annual number of vascular deaths by 8800 (6500 to 11100 ) or 9600 (7200 to 12900 ) respectively, $3 \%$ more than prescribing to everybody over 50 years. The number of adverse events is predicted to double to 2400 cases of myopathy, 400 of rhabdomyolysis, and 24400 excess diabetes diagnoses. The cost of statins would be $£ 360 \mathrm{~m}$, and that of apples $£ 480 \mathrm{~m}$. If compliance with apple prescriptions was $90 \%$, the number of vascular deaths averted would increase to 11000 (8100 to 13900 ); this is $29 \%$ more than with $70 \%$ compliance, costing $£ 339 \mathrm{~m}$ in apples. Finally, if the apple prescription has no effect on any aspect of the average diet except amount of fruit consumed, annual vascular deaths would reduce by 7100 (5000 to 9400), 20\% fewer than if dietary compensation occurs; costs would remain the same.

\section{Discussion}

Prescribing either an apple a day or a statin a day to everyone over 50 years old is likely to have a similar effect on population vascular mortality. Choosing apples rather than statins may 
avoid more than a thousand excess cases of myopathy and more than 12000 excess diabetes diagnoses. The basic costs of apples are likely to be greater than those of statins; however, NHS prescription prices and convenience may drive people to purchase their apples from a store rather than through a pharmacy, thereby reducing direct NHS costs, or the NHS may be able to negotiate apple price freezes (although defrosted apples may not be so palatable). ${ }^{23}$

\section{Strengths and limitations}

The strengths of this study lie in the underlying data used to parameterise the population effect of statins and the PRIME model, which came from meta-analyses of trials and prospective cohort studies (see web appendix for further details of the PRIME model). ${ }^{412-15}$

The exact definition of vascular mortality used differs slightly between the Cholesterol Treatment Trialists and the PRIME model. However, the most common causes of vascular death (ischaemic heart disease and stroke) are modelled for both statins and apples, making any remaining differences negligible in their effect size.

When estimating adverse events, as the Cholesterol Treatment Trialists note, the reduction in the number of vascular events due to the increased use of statins vastly outweighs the excess incidence of haemorrhagic stroke and diabetes. ${ }^{4}$ However, limitations of the Cholesterol Treatment Trialists' meta-analysis have been suggested, including underestimation of side effects and absence of an effect on all cause mortality for patients at low risk. ${ }^{24}$ This would suggest that our estimates of side effects from statins are conservative and that an added benefit of apples over statins may exist in terms of all cause mortality.

Our estimates of costs apply only to the basic cost of the intervention. We make no estimate of the cost to the health service of either accessing prescriptions or managing side effects.

The predicted effects of a change in national policy to provide statins to everybody aged over 50 could vary for several reasons. Although a conservative estimate, treatment compliance may be less than $70 \%$ in a population who may think of themselves as not needing the treatment. However, the shock effect of the policy may stimulate more people who are eligible for treatment but are not accessing it to seek medical care. Furthermore, compliance may reduce over time, meaning our results could overestimate future benefits and future adverse events. We also apply the same treatment effect on vascular mortality to people of all ages, sexes, and cardiovascular risk profiles, and in reality these may differ. ${ }^{21} \mathrm{We}$ assume that the age and sex distribution of the population taking of statins in the UK is the same as that found in the Health Survey for England. ${ }^{10}$

The estimate of population compliance with an apple a day is less evidence based. Although apples are of course both delicious and nutritious, this view is not consistently shared across the population; as much as $69 \%$ of UK adults do not meet the recommendation of five portions of fruit and vegetables a day. ${ }^{25}$ Whether this is due to the difficulty of accessing fresh fruit and vegetables, costs, or simply preference is unclear, but access through a pharmacy may go some way to reducing these barriers. Despite $69 \%$ of adults not getting their five a day, only $10 \%$ eat less than one portion a day ${ }^{22}$; our sensitivity analysis that assumes the remaining $90 \%$ could manage an extra portion suggests that as many as 11000 vascular deaths could be averted annually. Equally challenging may be the increased time and difficulty associated with consuming an apple compared with a statin—statins need a glass of water and a quick gulp, whereas apples require the more complex and time consuming process of coordinated mastication and swallowing.

Further limitations of this research are that fruit costs were taken in the autumn (a relatively cheap season) but are likely to vary around the year, and people may save money by spending less on their weekly shopping trip. The uncertainty estimates surrounding changes in mortality do not represent uncertainty associated with compliance or with the structural uncertainty of the PRIME model. Total calories consumed are assumed to remain the same in the apple model, consistent with previous modelling research, ${ }^{26}$ but what people may substitute their apple for is unclear. We assumed that the nutritional components of the average diet (table $2 \Downarrow$ ) would proportionately reduce by the increase in calories from $100 \mathrm{~g}$ of apple, but people might choose to remove other fruits from their diet instead. Having said this, if just $31 \%$ of the population are having five portions of fruit and vegetables a day in the first place, such substitutions may not be an option for many people. People may also choose to consume fewer total calories by replacing foods with a higher energy density with the low energy dense apple, potentially leading to even greater benefits on vascular mortality through reduced body mass index..$^{27}$ Furthermore, increased fruit consumption is related to reduced risk of various cancers, again adding to the apple's health benefits. ${ }^{28}$ Our sensitivity analysis that assumes no change in population diet except in the quantity of fruit consumed predicts 7100 fewer vascular deaths a year, with the $95 \%$ credible intervals still overlapping the effect size estimated from increased statin prescriptions.

Finally, we have not estimated the potential wider benefits of more than 12 million extra statin prescriptions to the drug industry and the jobs that would create, the boost to the apple farming industry of around 22 million extra daily requests for apples, or the effect on quality of life of fewer non-fatal vascular events.

\section{Meaning of study}

This study shows that small dietary changes as well as increased use of statins at a population level may significantly reduce vascular mortality in the UK. The five a day campaign to increase UK fruit and vegetable consumption is laudable in its aims and has the potential to deliver true population health benefits. ${ }^{29}{ }^{30}$ However, the UK is yet to adopt drug prescribing as a population level approach to primary prevention; current guidelines only affecting people at high risk of a cardiovascular event. $^{2}$ This research adds weight to calls for the increased use of pharmacological interventions for primary prevention of cardiovascular disease, as well as for persevering with policies aimed at improving the nutritional quality of UK diets.

\section{Conclusions}

The comparison of a medicalised approach to chronic disease prevention with that of a lifestyle one has been previously estimated (polypill versus polymeal), although, in our view, not with any realistic hope of changing population behaviour, despite the suggestion to employ out of work cardiologists as chefs. ${ }^{31}$ We offer a simplified version of this: our study suggests that both nutritional and pharmaceutical population approaches to primary prevention of vascular disease have the potential to have a significant effect on population mortality. We find that a 150 year old proverb is able to match modern medicine and is likely to have fewer side effects. Now to model the effect of inquisitiveness on feline mortality rates. 


\section{What is already known on this topic}

Trial data show that statins reduce the risk of vascular events irrespective of baseline cardiovascular disease risk An apple a day keeps the doctor away

\section{What this study adds}

An apple a day or a statin a day is equally likely to keep the doctor away

We acknowledge Lennert Veerman for his contribution to suggestions regarding the modelling of adverse events.

Contributors: ADMB devised a different study involving superheroes; PS expanded the idea and wanted to do that one. ADMB instead devised this study and talked PS out of the other one. Therefore, for this study, PS developed the PRIME model. ADMB and AM completed the modelling, and ADMB drafted the manuscript. ADMB and PS contributed to the study design. ADMB, PS, and AM reviewed and critiqued the final manuscript. PS will have to wait until next year to write a paper about superheroes. ADMB is unlikely to help him, but AM could be talked around to the idea. ADMB is the guarantor.

Funding: No explicit funding for this work was sought. ADMB is a National Institute for Health Research funded academic clinical fellow in public health. PS and AM are funded by the British Heart Foundation. The funders had no role in the design, process, or reporting of this study. Competing interests: All authors have completed the ICMJE uniform disclosure form at www.icmje.org/coi_disclosure.pdf and declare: no support from any organisation for the submitted work; PS has received research grants from the British Heart Foundation; ADMB eats five a day, AM tries to, and PS is a vegetarian; all diets include apples; neither ADMB, AM, nor PS takes statins, and all purport to be under 50 years old.

Ethical approval: This study used routinely collected publicly available datasets; ethics approval was not needed.

Transparency declaration: The lead author (the manuscript's guarantor) affirms that this manuscript is an honest, accurate, and transparent account of the study being reported; that no important aspects of the study have been omitted; and that any discrepancies from the study as planned (and, if relevant, registered) have been explained.

Data sharing: All data used in this study are freely available secondary data sets.

$1 \quad$ Notes and Queries Magazine 1866 Feb 24:153.

2 National Institute for Health and Clinical Excellence. Lipid modification: cardiovascular risk assessment and the modification of blood lipids for the primary and secondary prevention of cardiovascular disease. NICE clinical guideline 67. NICE, 2008 (modified 2010).

3 Wald NJ, Law MR. A strategy to reduce cardiovascular disease by more than $80 \%$. BMJ 2003;326:1419.

4 Cholesterol Treatment Trialists' (CTT) Collaborators. The effects of lowering LDL cholesterol with statin therapy in people at low risk of vascular disease: meta-analysis of individual data from 27 randomised trials. Lancet 2012:380:581-90.

5 Ebrahim S, Casas JP. Statins for all by the age of 50 years? Lancet 2012;380:545-7.

6 Office for National Statistics. Deaths registered in England and Wales in 2010, by cause. ONS, 2011.

7 General Register Office for Scotland. Section 6: Deaths—causes. In: Vital events reference tables 2010. General Register Office for Scotland, 2011.

8 Northern Ireland Statistics and Research Agency. Births and deaths reports, 2010. Northern Ireland Statistics and Research Agency, 2011.

9 Office for National Statistics. 2011 Census: population estimates for United Kingdom, 27 March 2011. ONS, 2012
10 Health and Social Care Information Centre. The Health Survey for England 2011. Stationery Office, 2011.

11 Taylor F, Huffman MD, Macedo AF, Moore TH, Burke M, Davey Smith G, et al. Statins for the primary prevention of cardiovascular disease. Cochrane Database Syst Rev 2013;1:CD004816.

12 Scarborough P, Morgan R, Webster P, Rayner M. Differences in coronary heart disease, stroke and cancer mortality rates between England, Wales, Scotland and Northern Ireland: the role of diet and nutrition. BMJ Open 2011;1:e000263.

13 Nichols M, Scarborough P, Allender S, Rayner M. What is the optimal level of population alcohol consumption for chronic disease prevention in England? Modelling the impact of changes in average consumption levels. BMJ Open 2012;2:e000957.

14 Scarborough P, Allender S, Clarke D, Wickramasinghe K, Rayner M. Modelling the health impact of environmentally sustainable dietary scenarios in the UK. Eur J Clin Nutr 2012:66:710-5.

15 Briggs A, Kehlbacher A, Tiffin R, Garnett T, Rayner M, Scarborough P. Assessing the impact on chronic disease of incorporating the societal cost of greenhouse gases into the price of food: an econometric and comparative risk assessment modelling study. BMJ Open 2013;3:e003543.

16 Department for the Environment, Food and Rural Affairs. Family food 2010. DEFRA, 2011.

17 Dauchet L, Amouyel P, Hercberg S, Dallongeville J. Fruit and vegetable consumption and risk of coronary heart disease: a meta-analysis of cohort studies. J Nutr 2006;136:2588-93

18 Dauchet L, Amouyel P, Dallongeville J. Fruit and vegetable consumption and risk of stroke: a meta-analysis of cohort studies. Neurology 2005:65:1193-7.

19 British Medical Association, Royal Pharmaceutical Society of Great Britain. British national formulary. BMA, RPS, 2013. (No 66.)

20 Department for the Environment, Food and Rural Affairs. Wholesale fruit and vegetable prices 23 September 2013. www.gov.uk/government/publications/wholesale-fruit-andvegetable-prices.

21 Collins GS, Altman DG. Predicting the 10 year risk of cardiovascular disease in the United Kingdom: independent and external validation of an updated version of QRISK2. BMJ 2012:233:e4181.

22 NHS Information Centre. The Health Survey for England 2008. Volume 1: physical activity and fitness. Stationery Office, 2009

23 Department of Health. Government agrees breakthrough drug pricing deal with pharmaceutical firms. 2013. www.gov.uk/government/news/government-agreesbreakthrough-drug-pricing-deal-with-pharmaceutical-firms.

24 Abramson JD, Rosenberg HG, Jewell N, Wright JM. Should people at low risk of cardiovascular disease take a statin? BMJ 2013;247:f6123

25 Department of Health. National Diet and Nutrition Survey: headline results from years 1 , 2 and 3 combined (2008/09 - 2010/11). DH, 2012.

26 Scarborough P, Nnoaham K, Clarke D, Capewell S, Rayner M. Modelling the impact of a healthy diet on cardiovascular disease and cancer mortality. J Epidemiol Community Health 2012;66:420-6.

27 Williams RA, Roe LS, Rolls BJ. Comparison of three methods to reduce energy density: effects on daily energy intake. Appetite 2013;66:75-83

28 American Institute for Cancer Research, World Cancer Research Fund. Food, nutrition, physical activity and the prevention of cancer: a global perspective. AICR, 2007.

29 NHS choices. 5 a day. 2013. www.nhs.uk/LiveWell/5ADAY/Pages/5ADAYhome.aspx.

30 Capacci S, Mazzocchi M. Five-a-day, a price to pay: an evaluation of the UK program impact accounting for market forces. J Health Econ 2011;30:87-98.

31 Franco OH, Bonneux L, de Laet C, Peeters A, Steyerberg EW, Mackenbach JP. The polymeal: a more natural, safer, and probably tastier (than the polypill) strategy to reduce cardiovascular disease by more than 75\%. BMJ 2013;329:1447.

Accepted: 27 November 2013

\section{Cite this as: BMJ 2013;347:f7267}

This is an Open Access article distributed in accordance with the Creative Commons Attribution Non Commercial (CC BY-NC 3.0) license, which permits others to distribute, remix, adapt, build upon this work non-commercially, and license their derivative works on different terms, provided the original work is properly cited and the use is non-commercial. See: http://creativecommons.org/licenses/by-nc/3.0/. 


\section{Tables}

Table 1| Nutritional composition of $100 \mathrm{~g}$ of apple $\mathbf{e}^{16}$

\begin{tabular}{lc} 
Nutritional component & Amount per $\mathbf{1 0 0} \mathrm{g}$ of apple \\
Energy (kcal) & 35.4 \\
\hline Fat $(\mathrm{g})$ & 0.09 \\
\hline Saturated fatty acids $(\mathrm{g})$ & 0.02 \\
\hline Monounsaturated fatty acids $(\mathrm{g})$ & 0.01 \\
\hline Polyunsaturated fatty acids $(\mathrm{g})$ & 0.05 \\
\hline Cholesterol $(\mathrm{mg})$ & 0.00 \\
\hline Fibre $(\mathrm{g})$ & 1.39 \\
\hline Salt $(\mathrm{g})$ & 0.00
\end{tabular}


Table 2| Nutritional composition of baseline UK $\operatorname{diet}^{16}$ and diet after introduction of an apple a day

$\begin{array}{lccc}\text { Nutritional component } & \text { Baseline diet } & \text { With an apple a day (calorie neutral) } & \text { No change except for fruit (sensitivity } \\ \text { analysis) }\end{array}$

*Daily increase in weight of fruit and vegetables consumption is not exactly $100 \mathrm{~g}$, as total calorie consumption is assumed to remain the same meaning a small reduction in consumption from other fruits and vegetables. 